
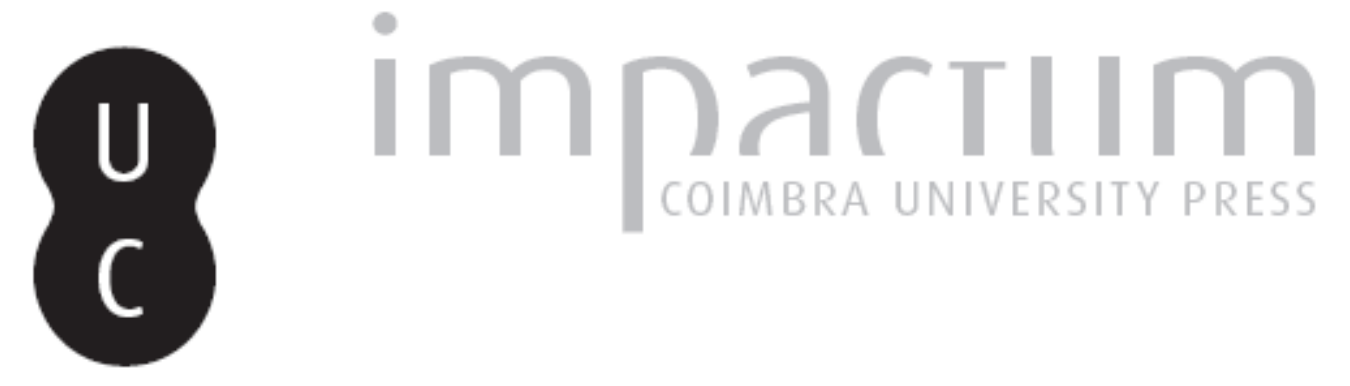

\title{
Recomendações gerais para a realização de relatórios periciais de clínica forense no âmbito do Díreito Civil
}

Autor(es): $\quad$ Magalhães, Teresa; Vieira, Duarte Nuno

Publicado por: Imprensa da Universidade de Coimbra

URL persistente:

URI:http://hdl.handle.net/10316.2/33173

DOI:

DOI:http://dx.doi.org/10.14195/1647-8630_20_9

Accessed : $\quad$ 26-Apr-2023 15:30:19

A navegação consulta e descarregamento dos títulos inseridos nas Bibliotecas Digitais UC Digitalis, UC Pombalina e UC Impactum, pressupõem a aceitação plena e sem reservas dos Termos e Condições de Uso destas Bibliotecas Digitais, disponíveis em https://digitalis.uc.pt/pt-pt/termos.

Conforme exposto nos referidos Termos e Condições de Uso, o descarregamento de títulos de acesso restrito requer uma licença válida de autorização devendo o utilizador aceder ao(s) documento(s) a partir de um endereço de IP da instituição detentora da supramencionada licença.

Ao utilizador é apenas permitido o descarregamento para uso pessoal, pelo que o emprego do(s) título(s) descarregado(s) para outro fim, designadamente comercial, carece de autorização do respetivo autor ou editor da obra.

Na medida em que todas as obras da UC Digitalis se encontram protegidas pelo Código do Direito de Autor e Direitos Conexos e demais legislação aplicável, toda a cópia, parcial ou total, deste documento, nos casos em que é legalmente admitida, deverá conter ou fazer-se acompanhar por este aviso.

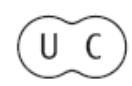




\title{
Recomendações gerais para a realização de relatórios periciais de clínica forense no âmbito do Direito Civil
}

\author{
Teresa Magalhães ${ }^{1,2,3,4}$, Duarte Nuno Vieira ${ }^{4,5,6}$
}

\section{Introdução}

A deficiente realização de um exame médico-legal e/ou a elaboração pouco cuidada e rigorosa do respectivo relatório pericial, podem colocar em causa o valor médico-legal da perícia. Tendo em consideração este facto e porque compete ao Instituto Nacional de Medicina Legal, I.P. (INML), garantir a qualidade das perícias realizadas, elaboraram-se um conjunto de recomendações e orientações, as quais pretendem auxiliar os peritos envolvidos nesta actividade a elaborarem, com correcção e rigor, relatórios periciais de Clínica Forense no âmbito do Direito Civil, perspectivadas já no âmbito do que se vem convencionando designar por nova nomenclatura dos parâmetros de dano.

Assim, são objectivos do presente trabalho, ajudar a identificar, descrever, interpretar e valorar os danos temporários e permanentes, de acordo com as normas definidas pelo INML para as perícias que decorrem no âmbito do Direito Civil e no contexto do preconizado pela Confederação Europeia de Especialistas em Avaliação e Reparação do Dano Corporal (CEREDOC), tendo em vista contribuir, através de uma detalhada e fundamentada análise técnico-científica da situação, para o melhor esclarecimento da Justiça.

* Normas aprovadas pelo Conselho Directivo do Instituto Nacional de Medicina Legal, I.P., em 25.11.2009 e ratificadas pelo Colégio de Especialidade da Ordem dos Médicos.

Delegação do Norte do Instituto Nacional de Medicina Legal, I.P.

2 Faculdade de Medicina da Universidade do Porto

3 Instituto Ciências Biomédicas Abel Salazar da Universidade do Porto

4 Centro de Ciências Forenses - Fundação para a Ciência e Tecnologia

5 Faculdade de Medicina da Universidade de Coimbra

6 Instituto Nacional de Medicina Legal, I.P. 
O âmbito destas recomendações é, pois, a perícia médico-legal para avaliação do dano na pessoa (classicamente designado por dano corporal), em sede de Direito Civil. Esta directiva aplica-se aos exames periciais efectuados nos serviços médico-legais (Delegações e gabinetes médico-legais do INML) e aos exames periciais efectuados por médicos contratados para o exercício de funções periciais junto tribunais.

\section{Recomendações}

Depois da identificação e descrição do dano no relatório pericial (ver procedimento $\mathrm{n}^{\circ} 1.1$ ), importará proceder à sua interpretação e valoração (nomeadamente qualitativa e quantitativa, consoante o parâmetro de dano em causa) concretizada à luz das normas legalmente definidas para a avaliação do dano na pessoa.

$\mathrm{Na}$ avaliação do dano corporal de natureza cível, contemplam-se danos temporários e permanentes, patrimoniais (económicos) e não patrimoniais (não económicos), dentro do princípio geral da reparação integral dos danos, importando que esta valoração seja, como sempre, isenta, imparcial e o mais objectiva e fundamentada possível, definindo-se os conceitos usados e identificando-se os métodos e técnicas utilizados. A valoração dos diversos parâmetros de dano é feita a nível do capítulo "Discussão". Deste capítulo devem constar:

\subsection{Danos temporários}

a) Défice funcional temporário

Corresponde ao período durante o qual a vítima, em virtude do processo evolutivo das lesões no sentido da cura ou da consolidação, viu condicionada a sua autonomia na realização dos actos correntes da vida diária, familiar e social (exclui-se aqui a repercussão na actividade profissional).

Poderá ser total ou parcial, coincidindo a primeira situação com os períodos de internamento e/ou de repouso absoluto, e iniciando-se a segunda logo que a evolução das lesões passe a consentir algum grau de autonomia na realização desses actos, ainda que com limitações.

Descreve-se em número de dias de défice funcional temporário total e de défice funcional temporário parcial, determinados com base na análise dos registos clínicos relativos à situação (hospitalares, do médico assistente, da seguradora, etc.), do quadro clínico concreto, da informação obtida (a partir do sinistrado, familiares, acompanhante, etc.) e das limitações natural- 
mente decorrentes da situação clínica. No caso de não existirem elementos suficientemente esclarecedores (muito particularmente registos clínicos), deve apreciar-se este parâmetro de dano com base nos períodos de tempo de défice funcional temporário total e de défice funcional temporário parcial habitualmente esperáveis para um quadro lesional similar ao verificado, tendo em consideração a situação clínica concreta e respectiva evolução. Para tal - e a título meramente de referência indicativa - pode recorrer-se a tabelas que facultam uma estimativa temporal deste dano, como por exemplo as de Ramírez (1996) ou de Pérez (2006).

Algumas situações clínicas podem envolver vários períodos de défice funcional temporário total e de défice funcional temporário parcial, decorrentes, por exemplo, de internamentos intermitentes por eventuais complicações, recaídas, recidivas ou cirurgias (designadamente para extracção de material de osteossíntese). Estes deverão ser fundamentados e explicitados no capítulo "Discussão" do relatório pericial, assinalando-se posteriormente nas conclusões o número total de dias correspondentes a cada um deles.

As incontornáveis dificuldades na fixação objectiva de taxa(s) de défice funcional temporário parcial justificam que, pericialmente, se determine apenas o número de dias a ele correspondente, sem se proceder a qualquer valoração numérica em pontos.

\section{b) Repercussão temporária nas actividades profissionais}

Corresponde ao período durante o qual a vítima, em virtude do processo evolutivo das lesões no sentido da cura ou da consolidação, viu condicionada a sua autonomia na realização dos actos inerentes à sua actividade profissional habitual. Poderá ser total ou parcial.

O tempo de repercussão temporária absoluta (total) nas actividades profissionais envolverá desde logo os períodos de internamento e/ou de repouso absoluto, entre outros, passando a repercussão temporária parcial nas actividades profissionais logo que a evolução das lesões consinta algum grau de autonomia na realização dessas mesmas actividades, ainda que com limitações.

Valora-se em número de dias de interrupção temporária absoluta das actividades profissionais e número de dias em que as mesmas foram concretizadas com limitações, determinados com base na análise dos registos clínicos relativos à situação (hospitalares, do médico assistente, da seguradora, etc.), do quadro clínico concreto, da informação obtida (a partir do sinistrado, familiares, acompanhante, entidade patronal, etc.) e das limitações naturalmente decorrentes da situação clínica. No caso de não existirem elementos suficientemente esclarecedores (muito particularmente registos clínicos), deve apreciar-se este parâmetro de dano com base nos períodos de tempo 
habitualmente esperáveis para cada um deles no âmbito de um quadro lesional similar ao verificado, tendo em consideração a situação clínica concreta e respectiva evolução. Para tal - e a título meramente de referência indicativa pode recorrer-se a tabelas que facultam uma estimativa temporal deste dano, como por exemplo as de Ramírez (1996) ou de Pérez (2006).

Algumas situações clínicas podem envolver vários períodos de interrupção temporária absoluta (total) ou de repercussão temporária parcial nas actividades profissionais, decorrentes, por exemplo, de internamentos intermitentes por eventuais complicações, recaídas, recidivas ou cirurgias (designadamente para extracção de material de osteossíntese), os quais deverão ser fundamentados e explicitados no capítulo "Discussão" do relatório pericial, assinalando-se nas conclusões deste o número total de dias correspondentes a cada um deles.

No caso dos estudantes deve referir-se o período de repercussão temporária na sua actividade de formação. Já relativamente à situação das domésticas ou de pessoas com actividades ocupacionais, lucrativas ou de subsistência, deve referir-se o período de afectação dessas actividades. Sublinhe-se que nestes casos será importante que a análise destas repercussões envolva também uma caracterização do "tipo" de repercussão, como, por exemplo, a dependência para o transporte ou faltas frequentes para tratamentos, ou a necessidade de apoio de terceiros para as actividades habituais no caso de domésticas.

Note-se que os períodos de défice funcional temporário podem não coincidir com os períodos de repercussão nas actividades profissionais.

\section{c) Quantum doloris}

Constitui um parâmetro de dano que corresponde à valoração do sofrimento físico e psíquico vivenciado pela vítima durante o período de danos temporários (entre a data do evento e a cura ou consolidação das lesões). Excepcionalmente, e nas circunstâncias adiante assinaladas, poderá ser valorado também como dano permanente.

Para esta valoração é fundamental a entrevista médica que deve permitir apreender a vivência do traumatismo sofrido pela vítima (circunstâncias peri e pós-traumáticas).

Como critérios de valoração deverão nomeadamente ser tomados em consideração os seguintes:

- Natureza e contexto do evento traumático, suas circunstâncias e eventos imediatos;

- Tipo e número de lesões e de tratamentos instituídos;

- Duração do(s) internamento(s) e número de intervenções cirúrgicas;

- Complicações médicas e cirúrgicas;

- Duração e complexidade do período de reabilitação funcional. 
Devem ainda ser considerados os sentimentos vivenciados pela vítima durante esse período, isto é, os sofrimentos psíquicos representados pelas perturbações e fenómenos emocionais decorrentes da situação, designadamente em termos de angústia, ansiedade, medo, consciência do perigo de vida, sofrimento pelo afastamento do meio familiar e das actividades profissionais, e que o médico sabe estarem habitualmente ligados à natureza das lesões e à sua evolução.

Devem também ser ponderados e tidos em consideração elementos indirectos de informação, como seja por exemplo, a medicação concretizada ao longo dessa fase, e a sua plausibilidade em termos clínicos.

Note-se que esta avaliação se poderá incluir o sofrimento psíquico decorrente de um dano estético temporário ou de um prejuízo sexual temporário.

A sua valoração será expressa através de uma escala quantitativa de sete graus de gravidade crescente (1/7 a 7/7), podendo recorrer-se, a título orientativo, a tabelas indicativas do quantum de dor correspondente a cada situação lesional, nomeadamente e por exemplo, à Tabela de Thierry e Nicourt.

É obrigatória a fundamentação da valoração atribuída a este parâmetro de dano.

Como foi anteriormente referido, nos casos absolutamente excepcionais em que se verifique a persistência de dor sem que esta implique qualquer limitação funcional (isto é, uma afectação permanente da integridade físico-psíquica com tradução numa valoração em pontos) ou esteja contida nos restantes parâmetros de dano permanente que irão ser seguidamente analisados, poderá perspectivável a valoração de um Quantum Doloris a título de dano permanente. Haverá, todavia, que reconhecer que se trata de situações tão excepcionais e de dificílima comprovação pericial, que a sua apreciação na prática médico-legal acaba por não ocorrer.

\subsection{Danos permanentes}

\section{a) Afectação permanente da integridade físico-psíquica}

Trata-se de um parâmetro de dano que corresponde à afectação definitiva da integridade física e/ou psíquica da pessoa, constitutiva de um défice funcional permanente com eventual repercussão nas actividades da vida diária, incluindo as familiares e sociais, e sendo independente das actividades profissionais. Corresponde ao dano que vinha sendo tradicionalmente designado por incapacidade permanente geral (nomeadamente no Anexo II do Decreto-Lei $n^{\circ} 352 / 2007$, de 23 de Outubro) e referido na Portaria $n^{\circ} 377 / 2008$, de 26 de Maio, como dano biológico.

A afectação da integridade físico-psíquica constitui uma redução definitiva do potencial físico, psico-sensorial e/ou intelectual resultante de um 
dano anátomo-fisiológico medicamente constatável, e como tal apreciável através de um exame clínico apropriado, completado pelo estudo dos exames complementares eventualmente realizados, à qual se juntam os fenómenos dolorosos e as repercussões psicológicas normalmente associadas à alteração sequelar descrita, assim como as consequências na vida diária, objectiva e habitualmente associadas a essa alteração.

É avaliado relativamente à capacidade integral do indivíduo (100 pontos), podendo, eventualmente, traduzir-se num compromisso total dessa capacidade (ex.: estado vegetativo).

Deve ponderar-se em função das especificidades do caso concreto, a afectação permanente decorrente de um estado anterior.

Trata-se de um dano que, sendo personalizado, deve ser valorado de forma metodologicamente igual em todas as pessoas, independentemente da sua actividade profissional ou ocupacional. É determinado tendo em conta a globalidade das sequelas do caso concreto (corpo, funções e situações de vida) e tendo como elemento indicativo de referência, a Tabela de Avaliação de Incapacidades em Direito Civil (Anexo II do Decreto-Lei no 352/2007, de 23 de Outubro), de acordo com a experiência médico-legal relativamente a estes casos.

Esta Tabela (TIC) tem carácter meramente indicativo, não isentando o perito de fundamentar a avaliação feita, muito particularmente quando se afasta dos valores nela propostos, conforme resulta aliás da própria lei.

Na utilização da TIC devem atender-se às indicações seguintes:

- Valoriza-se não só o dano no corpo como a sua repercussão funcional e para as actividades da vida diária;

- Nas situações em que a TIC apenas contempla o défice completo, a avaliação de sequelas que impliquem apenas um défice parcial, deve ser feita tendo em consideração os pontos correspondentes à perda total;

- Na pontuação a atribuir a cada sequela, segundo o critério clínico, deve o perito ter em conta a sua intensidade e gravidade, do ponto de vista físico e bio-funcional, bem como o sexo e a idade da vítima;

- Cada sequela deve ser valorada apenas uma vez, mesmo que a sua sintomatologia se encontre descrita em vários capítulos, excepcionandose o caso do Dano Estético. Não se valorarão as sequelas que estejam incluídas ou derivem de outra, ainda que descritas de forma independente;

- As situações sequelares não descritas na tabela serão avaliadas por analogia, isto é, por comparação com as situações contempladas e quantificadas.

- É obrigatória a indicação no relatório do(s) número(s) de código e respectiva valorização a que se recorreu para a determinação do valor de cada sequela, bem como a metodologia usada para a determinação afectação da integridade físico-psíquica (prévia incapacidade permanente 
geral) - Regra da Capacidade Restante ou pontuação equivalente à afectação global do(s) órgão(s) ou função(ões) -, sendo sempre também obrigatória a fundamentação do afastamento dos valores propostos na TIC.

- Nas sequelas múltiplas sinérgicas, isto é, envolvendo a mesma função, deve proceder-se ao somatório directo da pontuação de cada uma delas, ajustando-se o valor final por comparação com a pontuação mais elevada correspondente à perda total da função ou órgão, que não poderá ser superada;

- Nas sequelas não sinérgicas, isto é, naquelas que envolvam órgão(s) e/ ou funções distintas, a determinação da afectação da integridade físicopsíquica deverá atender ao valor da afectação global do(s) órgão(s) ou função(ões), sendo que os pontos obtidos terão, necessariamente, de ser inferiores à soma das pontuações isoladas. Se, no caso das sequelas múltiplas, não for possível proceder desta forma, deve o perito recorrer à utilização da Regra da Capacidade Restante (Regra de Balthazar);

- Em casos devidamente fundamentados, pode o perito ajustar os valores obtidos através do cálculo da capacidade restante, por comparação com as pontuações correspondentes à perda dos órgãos ou funções em causa.

O perito estima um valor de afectação da integridade físico-psíquica, o qual, se resultar da aplicação da Regra de Balthazar deve ser ajustado à realidade do caso, atenta a avaliação efectuada e a experiência médico-legal do perito, tratando-se no entanto de um procedimento que visa ajustar, para cima ou para baixo, os pontos calculados. Estes deverão ser apresentados num número inteiro e não em valores aproximados às décimas ou centésimas, reforçando-se assim a ideia que se trata de um valor estimado e não aritmeticamente calculado, dada a falta de rigor absoluto deste tipo de cálculo quando aplicado à avaliação de danos na pessoa.

Além do que à utilização da TIC se refere, é obrigatória a fundamentação deste dano quer através da descrição correcta e pormenorizada das queixas e sequelas, nos respectivos capítulos, quer através da implicação deste dano na autonomia e independência da pessoa.

Deve ter-se a consciência plena de que a pontuação atribuída à afectação permanente da integridade físico-psíquica, não corresponde de forma alguma a uma unidade de medida rigorosa e absoluta, mas sim a uma unidade de apreciação. Com efeito, a pontuação a atribuir resultará da integração de medições de fenómenos diversos, concretizadas através de instrumentos também diversos e, como tal, expressas em unidades igualmente distintas, integrando ainda a opinião intuitiva do perito decorrente da sua experiência pessoal e da sua capacidade de apreensão dos imponderáveis.

Nos casos em que seja previsível a verificação de um Dano Futuro (considerando-se exclusivamente como tal o agravamento das sequelas que 
constitui uma previsão fisiopatologicamente certa e segura, por corresponder à evolução lógica, habitual e inexorável do quadro clínico), deve o perito fundamentar esta circunstância no capítulo “Discussão” do seu relatório pericial e assinalá-la nas "Conclusões” do mesmo.

As incontornáveis dificuldades na fixação objectiva de uma pontuação do Dano Futuro, justificam que pericialmente não se proceda a qualquer quantificação deste dano, assinalando-se apenas a sua verificação, tendo em vista deixar em aberto a eventualidade de uma reabertura do processo com posterior reavaliação.

\section{b) Repercussão na actividade profissional}

Corresponde ao rebate das sequelas no exercício da actividade profissional habitual da vítima (actividade à data do evento), isto é, na sua vida laboral, para utilizar a expressão usada na Portaria $n^{\circ}$ 377/2008, de 26 de Maio. Pode referir-se a uma modificação da formação prevista ou ao seu abandono, no caso de um estudante, por exemplo.

Podem verificar-se as seguintes situações relativamente ao estado sequelar:

- Ser compatível com o exercício da actividade profissional;

- Ser compatível com o exercício da actividade profissional mas implicando esforços suplementares;

- Ser impeditivo do exercício da actividade profissional, sendo no entanto compatível com outras profissões na área da sua preparação técnicoprofissional;

- Ser impeditivo do exercício da actividade profissional, bem assim como de qualquer outra dentro da área da sua preparação técnico-profissional.

A fundamentação deste dano é obrigatória, designadamente através da sua descrição correcta e pormenorizada no capítulo das queixas situacionais, no que às questões laborais diz respeito.

\section{c) Dano estético permanente}

Corresponde à repercussão das sequelas, numa perspectiva estática e dinâmica, envolvendo uma avaliação personalizada da afectação da imagem da vítima quer em relação a si próprio, quer perante os outros.

Pode ser um dano estético (ex.: cicatriz) ou dinâmico (ex.: claudicação da marcha), devendo ser tido em conta o seu grau de notoriedade e o desgosto manifestado/vivenciado pela vítima (considerada a sua idade, sexo, estado civil e estatuto sócio-profissional), e assinalada a sua eventual possibilidade de recuperação, designadamente cirúrgica. 
As dificuldades resultantes da dupla subjectividade nesta avaliação (por parte do perito e da vítima), atenuam-se descrevendo minuciosamente as sequelas quanto à sua localização, forma, dimensões, relevo, textura, coloração e número, e documentando-as fotograficamente (mediante prévia autorização da vítima) para que o juiz as possa também apreciar. Ainda assim, a avaliação terá de ser personalizada, dado que danos estéticos similares podem ter repercussões substancialmente diferentes.

A valoração do Dano Estético é expressa através de uma escala quantitativa de sete graus de gravidade crescente (1/7 a 7/7). Como sempre, é obrigatória a fundamentação deste dano, não só no capítulo da “Discussão" mas, também, através da descrição correcta e pormenorizada das queixas e sequelas, nos respectivos capítulos.

Como anteriormente referido, um dano estético temporário poderá ser incluído no âmbito da avaliação do Quantum Doloris.

\section{d) Repercussão na actividade sexual}

Corresponde à limitação total ou parcial do nível de desempenho/gratificação de natureza sexual, decorrente das sequelas físicas e/ou psíquicas, não se incluindo aqui os aspectos relacionados com a capacidade de procriação.

Este dano é frequentemente subavaliado ou não avaliado, dada a relevância de outras sequelas graves mas, sobretudo, devido a algum preconceito e reserva que ainda subsiste na abordagem deste tema, por parte de peritos e vítimas.

$\mathrm{Na}$ sua valoração, o perito deve atender particularmente aos elementos obtidos no decurso da entrevista, dando particular atenção ao teor do relato (ex: tipo de traumatismo) e ressonância afectiva, idade e estado anterior da vítima (ex: diabetes, insuficiência hepática ou renal, vasculopatias) e ao dano físico ou psicológico (epifenómeno do trauma).

Este dano pode manifestar-se através de perturbação da líbido, desconforto, disfunção eréctil, da ejaculação ou do orgasmo, sendo aconselhável, sempre que possível, objectivar estas queixas através de exames complementares.

A sua avaliação tem em conta as lesões iniciais, as complicações resultantes e os estudos complementares efectuados. Caso não seja medicamente constatável dano de etiologia orgânica, deve o perito pronunciar-se sobre a plausibilidade clínica das queixas, tendo como base os elementos anteriormente referidos e a vivência do trauma.

Este dano é distinto do dano na capacidade reprodutora que, a existir, será valorizado em pontos, no âmbito da alteração da integridade físico-psíquica.

Constitui, também, um dano não económico, quantificado numa escala com sete graus de gravidade crescente (1/7 a 7/7), cuja fundamentação é obrigatória não só no capítulo da Discussão mas, também, através da descrição 
correcta e pormenorizada das queixas (funcionais e situacionais) e sequelas, nos respectivos capítulos.

\section{e) Repercussão nas actividades desportivas e de lazer}

Corresponde à impossibilidade estrita e específica para a vítima de se dedicar a certas actividades lúdicas, de lazer e de convívio social, que exercia de forma regular e que para ela representavam um amplo e manifesto espaço de realização e gratificação pessoal. Não estão aqui em causa intenções ou projectos futuros, mas sim actividades comprovadamente exercidas previamente ao evento traumático em causa e cuja prática e vivência assumia uma dimensão e dignidade susceptível de merecer a tutela do direito, dentro do princípio da reparação integral dos danos. Está uma vez mais em causa o procurar apreender a vivência da vítima quanto à impossibilidade de dar continuidade àquilo que para ela constituía uma das suas razões de vida, um espaço de realização e gratificação pessoal, como anteriormente assinalado.

A sua valoração pode ser feita através de uma escala com sete graus de gravidade crescente (1/7 a 7/7).

Trata-se de um dano não económico, devendo ser sempre muito bem fundamentado, não só no capítulo da Discussão mas, também, através da descrição correcta e pormenorizada das queixas (sobretudo situacionais) e sequelas, nos respectivos capítulos.

\section{f) Dependências}

As dependências podem ser temporárias ou permanentes, sendo valorizadas mais frequentemente, enquanto tal, as permanentes.

Estas dependências podem ser relativas a diversos tipos de necessidades:

Ajudas medicamentosas: correspondem à necessidade permanente de recurso a medicação regular (ex: analgésicos, antiespasmódicos ou antiepilépticos), sem a qual a vítima não conseguirá ultrapassar as suas dificuldades em termos funcionais e nas situações da vida diária;

Tratamentos médicos regulares: correspondem à necessidade de recurso regular a tratamentos médicos para evitar um retrocesso ou agravamento das sequelas (ex.: fisioterapia);

- Ajudas técnicas: referem-se à necessidade permanente de recurso a tecnologia para prevenir, compensar, atenuar ou neutralizar o dano pessoal (do ponto de vista anatómico, funcional e situacional), com vista à obtenção da maior autonomia e independência possíveis nas 
actividades da vida diária; podem tratar-se de ajudas técnicas lesionais, funcionais ou situacionais;

- Adaptação do domicílio, do local de trabalho ou do veículo: corresponde à necessidade de recurso à tecnologia a nível arquitectónico, de mobiliário e/ou equipamentos, no sentido de permitir a realização de determinadas actividades diárias a pessoas que, de outra maneira, o não conseguiriam fazer (a não ser com a ajuda de terceiros);

- Ajuda de terceira pessoa: corresponde à ajuda humana apropriada à vítima que se tornou dependente, como complemento ou substituição na realização de uma determinada função ou situação de vida diária. $\mathrm{O}$ tipo de ajuda a perspectivar, deve ponderar-se de acordo com a categoria sócio-profissional necessária (técnica ou não), número e tipo de terceiras pessoas, sua qualificação e funções, tipo de intervenções (em casa e no exterior), tipo de actividades visadas (vigilância de parâmetros vitais, administração de terapêutica, higiene, vestuário, alimentação, etc.), local das intervenções (domicílio ou estabelecimento adaptado), grau e tipo de ajuda (vigilância, incitação, complemento ou substituição total) e duração e frequência/horário das intervenções (número de horas por dia).

Idealmente esta perícia é multidisciplinar e realizada no meio de vida da vítima (domicílio e local de trabalho), devendo incluir uma avaliação médica (análise das sequelas orgânicas, funcionais e, muito particularmente, situacionais) e uma avaliação das necessidades por técnicos especializados, tendo sempre em conta a capacidade restante e a autonomia com e sem ajudas técnicas.

Estas ajudas, sublinha-se novamente, podem ser temporárias ou definitivas.

Nestes casos, como acima referido, deve o perito solicitar a colaboração do Centro de Reabilitação Profissional de Gaia ou de outras entidades competentes, designadamente o Instituto do Emprego e Formação Profissional.

\section{Referências}

Boróbia C. Valoración del Daño Corporal. Legislación, Metodología y Prueba Pericial Médica. Barcelona: Masson; 2006.

Carol J. Valoración del Daño Corporal. Manual de Consulta. Atelier, Barcelona; 2006.

Lucas P, Bargagna M, Boróbia C, Béjui-Huges H, Streck W, Vieira DN. La rationalisation de l'évaluation européenne des atteints à la personne humaine, Revista Portuguesa de Avaliação do Dano Corporal 2001; 10 (11):21-35.

Magalhães T. Estudo Tridimensional do Dano Corporal: Lesão, Função e Situação. Sua Aplicação Médico-Legal. Coimbra: Almedina; 1998.

Magalhães T, Pinto da Costa D. Avaliação do dano na pessoa em sede de Direito Civil. Perspectivas actuais. Revista da Faculdade de Direito da Universidade do Porto 2007 ; 4:417-52. 
Oliveira Sá. Clínica Médico-Legal da Reparação do Dano Corporal em Direito Civil. Coimbra: APADAC; 1992.

Pérez MG-B. Nuevo Manual de Valoración y Baremación del Daño Corporal. $14^{\circ}$ ed. Granada: Editorial Comares; 2006.

Ramírez LB. Tiempos de Curación en Traumatologia. Madrid: Praxis 2.000; 1996.

Vieira DN. A "missão" de avaliação do dano corporal em direito civil. Sub Júdice 2000; 17:23-30.

Vieira DN. Assessment of bodily damage in civil law: harmonisation of an expert protocol, Revista Portuguesa de Avaliação do Dano Corporal 2003; 12 (13): 29-36.

Vieira DN, Quintero JA, Ed. Aspectos práticos da avaliação do dano corporal em Direito Civil. Coimbra: Biblioteca Seguros; 2008.

Decreto-Lei $n^{\circ} 352 / 2007$, de 23 de Outubro, Anexo II

Lei $\mathrm{n}^{\circ}$ 45/2004, de 19 de Agosto

Portaria $\mathrm{n}^{\circ}$ 522/2007, de 30 de Abril

Resumo: Recomendações gerais para a realização de relatórios periciais de clínica forense no âmbito do direito civil

Os autores apresentam as recomendações gerais que aprovaram a nível do Conselho Directivo do Instituto Nacional de Medicina Legal, I.P., para a realização de relatórios periciais de Clínica Forense no âmbito do Direito Civil.

Palavras-Chave: Relatório pericial; clínica forense; dano corporal; Direito Civil; boas-práticas.

Summary: General recommendations to perform clinical forensic medicine reports related with bodily harm assessment in civil law

Authors present the general recommendations which were approved by the Directive Council of the National Institute of Legal Medicine, to perform Clinical Forensic Medicine reports related with bodily harm assessment in Civil Law.

Key-Words: Forensic report; clinical forensic medicine; bodily harm; civil law; good-practice.

Résumé: Recommandations générales pour la réalisation de rapports de clinique medico-legale concernant le dommage corporel post-traumatique dans la cadre du droit civil Les auteurs présentent les recommandations générales qu'ils ont approuvé au niveau du Conseil Directive de l'Institut National de Médicine Légale, pour la réalisation de rapports de clinique médico-légale concernant le dommage corporel post-traumatique dans la cadre du Droit Civil.

Mots-Clés: Rapport médico-légal; clinique médico-légale; dommage corporel; droit Civil; bonnepratiques.

\section{Pedido de separatas:}

TERESA MAGALHÃES

imlfmup@gmail.com 